\title{
Optimizing monitoring network of water table by geostatistical methods
}

\author{
Hosein Abedian ${ }^{1}$, Kourosh Mohammadi ${ }^{2}$ and Ramin Rafiee ${ }^{3 *}$ \\ ${ }^{1}$ Shahid Beheshti University, Iran. \\ ${ }^{2}$ Department of Hydrology, Tarbiat modares University, 14115-111, Chamran Street, Tehran, Kourosh Iran. \\ ${ }^{3}$ Faculty of Petroleum and Geophysics, Shahrood University, Shahrood, Iran.
}

Accepted 30 August, 2013

\begin{abstract}
Data collection of alluvium aquifers is done by using quality-quantity networks because of their spread and continuity.In designing such a network, it is necessary to pay attention on distribution of variables all over the aquifer so that variables represent whole of aquifer correctly. This happens when the network is able to predict the affects of climatical, natural etc parameters on the aquifers. Besides it should provide the maximum amount of information of the studied aquifers. At present, these networks are designed based on some empirical parameters. As a result, these cannot correctly represent the aquifer and some scientific methods needs to be benefited from to modify the empirical methods. Therefore using geostatistical methods seems to be necessary. The major difference is that a relation can be detected between quantities of a variation in different samples and distance and direction of the samples, while in the statistical methods, the quantites are haphazardly. It means that in the statistical methods, quantity of the variation in one sample doesn't provide any information about its quantity in other samles. In this case study, using geostatistical methods, water table network is optimized for the aquifer of Ardestan Plain. Gaussian model - as the best fitted model on Kriging geostatistical method - is used in this case study. Optimization has two main steps: in the first step, using cross validation method, possibility of deleting some wells is studied based on the differences between predicted and measured values of them during a suitable statistical period; if the difference is negligible, these wells can be omitted, based on the iso-standard deviation map, and in the next step based on some suitable points, the best combination of points, by try \% error method and a computerized model is determined to be added to the network in such a way that estimations cause minimum standard deviation. At the end of this study, the network was optimized by deleting a piezometer and adding two other ones.
\end{abstract}

Key words: Geostatistical method, monitoring network, groundwater.

\section{INTRODUCTION}

Water table monitoring network (observation well network) is one of the most significant ones in monitoring aquifers. Excavation, reinforcement, and periodic measurment of such monitorings are costly; besides they must be a perfect representative of the aquifers being monitered; accordingly determining location and layout of the observation wells needs to be taken seriously (Araghinejad and Burn 2005).
Nowadays, to estimate local variables such as water table in a region, a statistical method called geostatistics is used (Bogardi et al 1985). Major difference between this method and the statistical ones is that in statistical methods, the samples are independent and they don't give any information about the other samples, while geostatistical method examines the local correlation among the values of a variable in an area. The correlation 


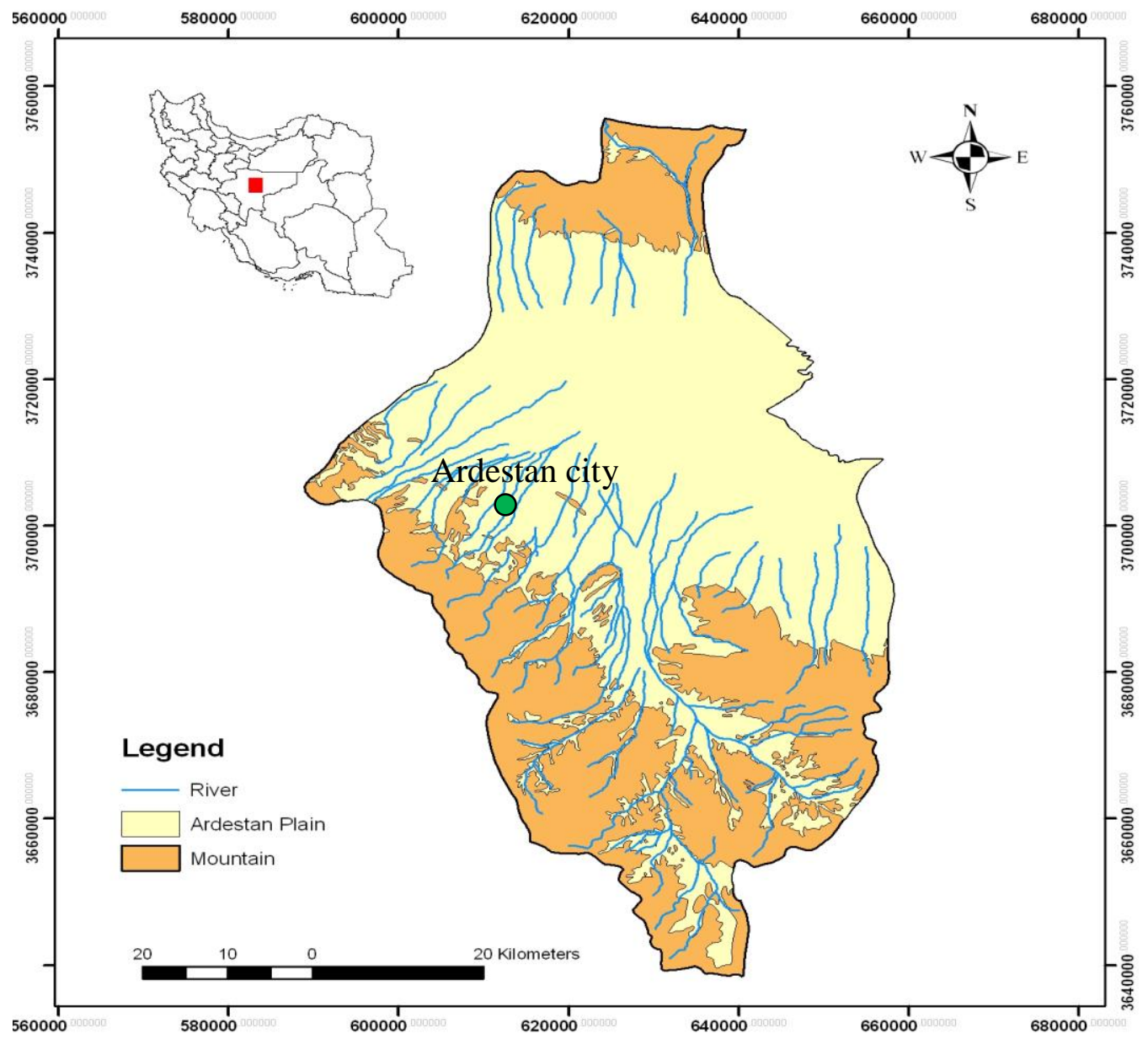

Figure 1. Study area.

is examined by variogram.

One of the geostatistical methods to estimate variables is kriging method, which has been named after a geostatistical science forerunners. Kriging is an estimation method based on the weighting average which can be considered as the Best Linear Unbiased Estimater (B.L.U.E) (Kumar 2006; Kitanidis 1995; Sophocleous et al 1982).

In this study, by using mentioned method in Ardestan area (Figure 1), the quantitative monitoring network has been optimized in such a way to be a perfect representative of the aquifer (Hughes and Lettenmaier 1984).

\section{EXTRACTING THE HYDROGRAPHS}

At the present time, in order to monitor water table of Ardestan plain, twenty six observation wells were used. This number in comparison with aquifer area $\left(1400 \mathrm{~km}^{2}\right)$ is approximately 0.46 of a $25 \mathrm{~km}^{2}$ network. First step of optimization is using complete and correct information of the network. By extracting hydrographs of the plain observation wells, oscillation of water level in these boreholes have been studied, so that if data has defect, it can be corrected by engineering judgments.

In next step, regarding the last phase of monitoring network completion of water table and unit hydrograph oscillation which shows descending trend during dry and wet years, geostatistical analyses (Araghinejad and Burn 2005) since water years 1998 to 1999 until 2011 to 2012 have been done (Hudak and Loaiciga 1993).

\section{ELIMINATION AND ADDING OF THE OBSERVATION WELLS}

In order to eliminate boreholes of the network, software $\mathrm{Gs}^{+}$has been used, in which information of the wells location and their relevant water table are needed. By entering data, in first step normalization of data dispersion has been examined and variogram of each month has been calculated (Figure 2a). Regarding characteristics of variogram, the best variogram state has been selected isotrop and the best fitted model on it has been selected Gaussian model (Table 1). Concerning information of variogram relevant to network in each month, and by 


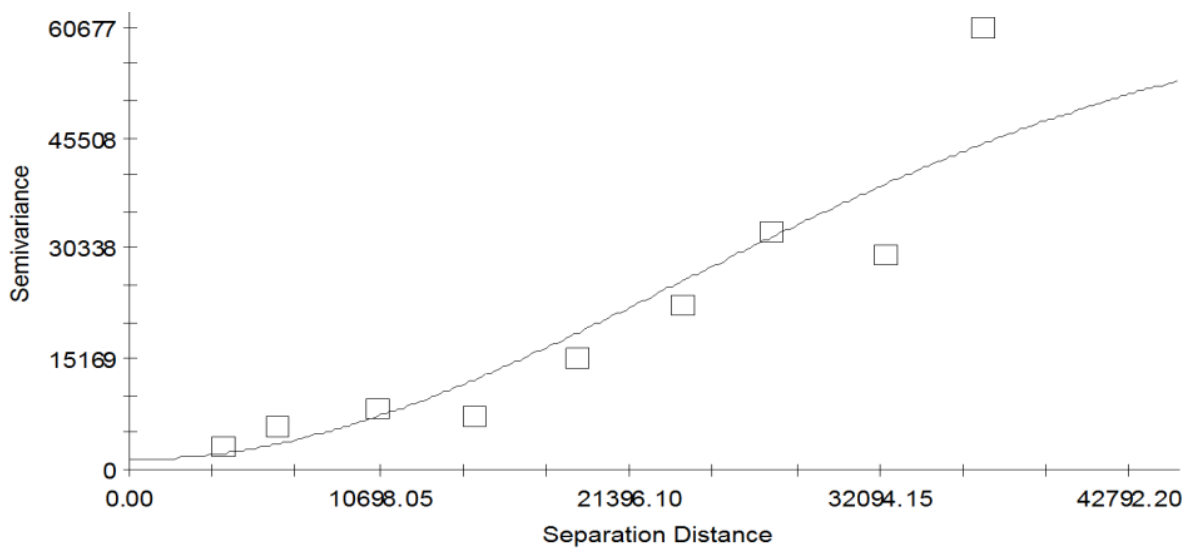

Gaussian model $(C o=1300.0000 ; \mathrm{Co}+\mathrm{C}=63700.0000 ; \mathrm{Ao}=33490.00 ; \mathrm{r} 2=0.854$; RSS $=4.098 \mathrm{E}+08$ ) (a)

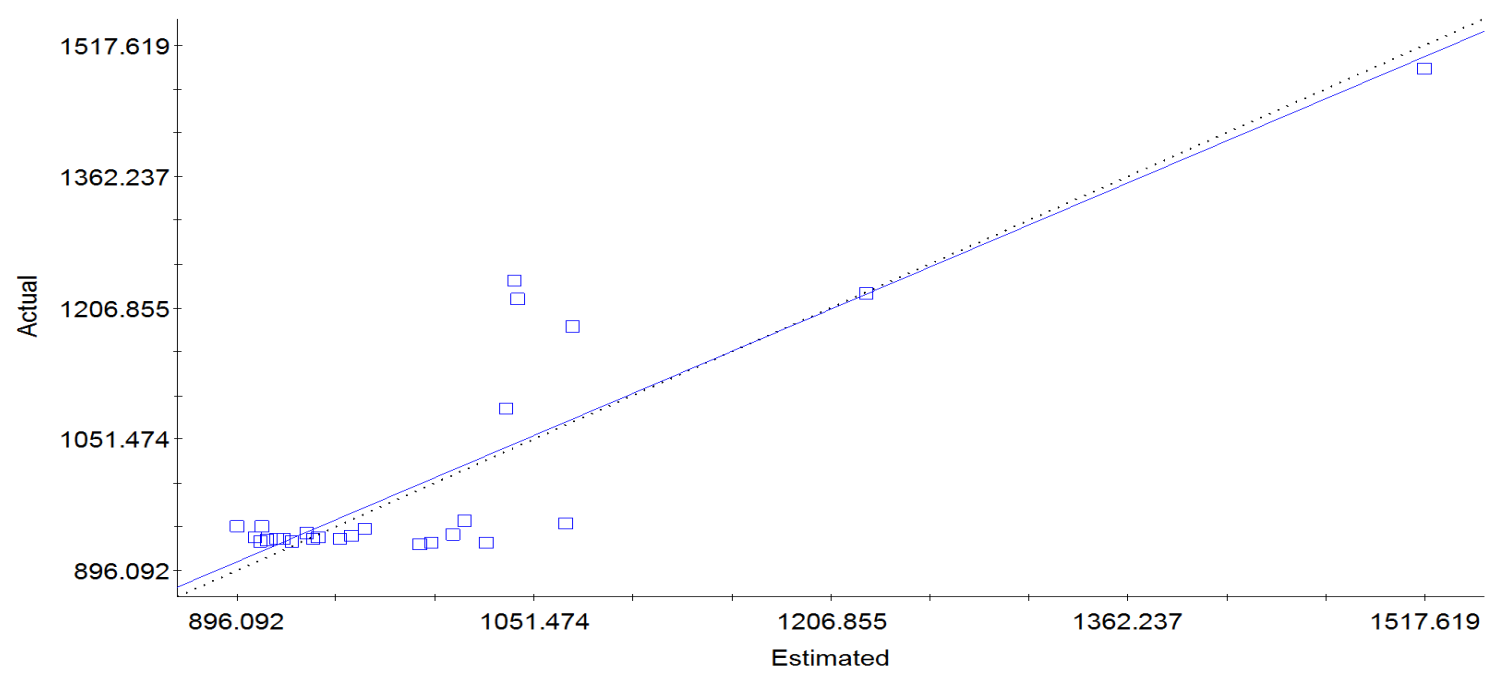

(b)

Figure 2. (a) Isotrope variogeram; (b) cross validation curve.

using Kriging equations, cross validation curve has been plotted for all months. This curve is obviously indicative of difference value between measured and estimated values of water table in each point of quantitative monitoring network of the aquifer.

Accordingly, observation well in which this difference is less, can be eliminated from network, since water table in this borehole can be estimated by using nearby observation well, Figure $2 \mathrm{~b}$ presents cross validation curve of Ardestan Plain in October, 2006.

During selected statistical period, analysis network and the borehole which shows the least difference between measured and estimated values were determined for each month. Table 2 shows results of observation well classification which are criterion of selecting eliminated borehole from network. Regarding performed analyses,
Kachoumesghal and Aliabad observation well are the best selections to be eliminated from the network. In the final phase, mentioned observation wells were eliminated from the network separately, and the network was analyzed, Figure 3 presents standard deviation map, before and after elimination of these two observations well from network in October, 2006.

Obviously, absence of Kachoumesghal borehole not only does not cause estimation error of water table to increase, but also causes standard deviation of the network to decrease, while elimination of Aliabad borehole would cause standard deviation to increase. This analysis has been performed in all months of statistical period which have resulted in same results. Therefore, it is suggested that in case of elimination necessity, just Kachoumesghal borehole would be 
Table 1. Characteristics of variogram models as well as error of each model (October, 2006).

\begin{tabular}{lccccccc}
\hline Model & $\begin{array}{c}\text { Nugget } \\
\left(\boldsymbol{C}_{\boldsymbol{0}}\right)\end{array}$ & $\begin{array}{c}\text { Sill } \\
\left(\boldsymbol{C}_{\boldsymbol{0}}+\boldsymbol{C}\right)\end{array}$ & $\begin{array}{c}\text { Renge parameter } \\
\left(\boldsymbol{A}_{\boldsymbol{0}}\right)\end{array}$ & $\begin{array}{c}\text { Effective } \\
\text { renge }\end{array}$ & $\begin{array}{c}\text { Proportion } \\
\left(\boldsymbol{C} / \boldsymbol{C}+\boldsymbol{C}_{\boldsymbol{0}}\right)\end{array}$ & $\boldsymbol{r}^{2}$ & RSS \\
\hline Spherical & 100 & 61300 & 75150 & 75150 & 0.998 & 0.804 & $4.67 \times 10^{3}$ \\
Exponential & 100 & 61300 & 37790 & 13370 & 0.998 & 0.81 & $7.55 \times 10^{3}$ \\
Linear & 100 & 61300 & 52730 & 52730 & 0.998 & 0.821 & $3.72 \times 10^{3}$ \\
Linear to sill & 100 & 61300 & 52730 & 52730 & 0.998 & 0.821 & $3.72 \times 10^{3}$ \\
Gaussian & 1300 & 63700 & 33800 & 58543 & 0.998 & 0.854 & $2.01 \times 10^{2}$ \\
\hline
\end{tabular}

Table 2. Results eliminated borehole from network during statistical period.

\begin{tabular}{lccc}
\hline Name & Number repeat & Percent & Deletion preference \\
\hline Kachoumesghal & 46 & 55.42 & 1 \\
Aliabad & 22 & 27.71 & 2 \\
Dashtiabad & 9 & 10.84 & 3 \\
Zavare & 3 & 3.61 & 4 \\
Mozdabad & 2 & 2.4 & 5 \\
\hline
\end{tabular}

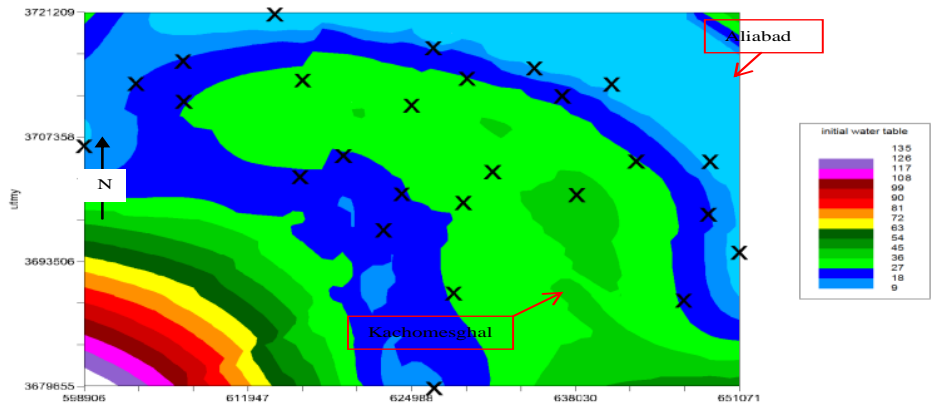

(a)

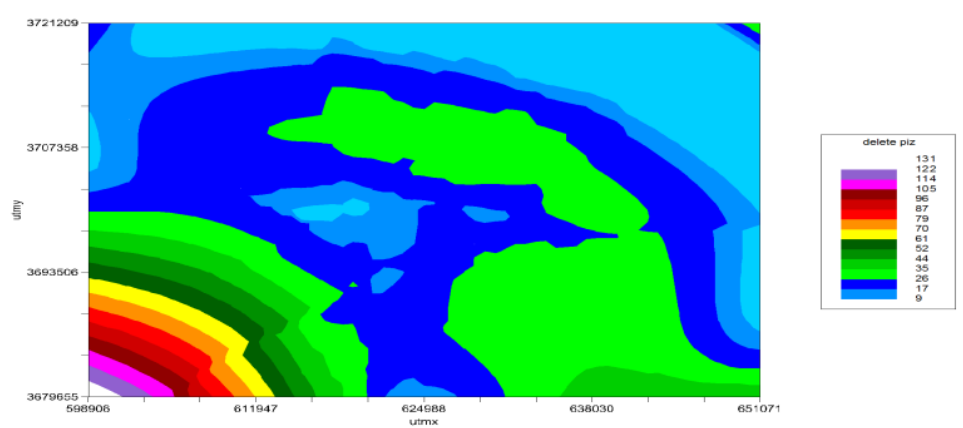

(b)

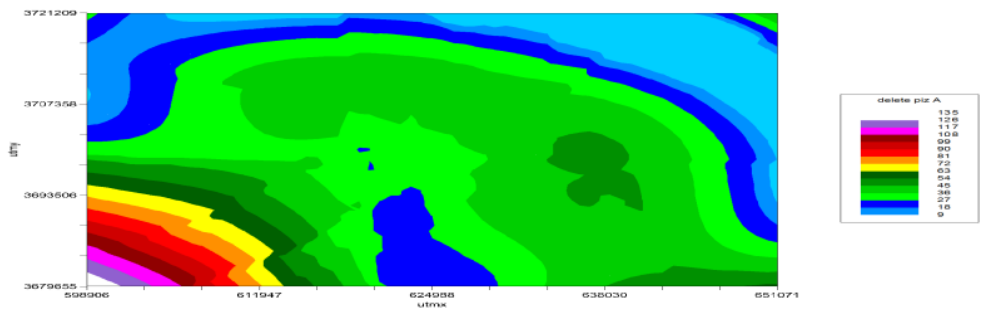

(c)

Figure 3. Iso standard deviation map. (a) initial network, (b) after elimination of Kachoumesghal, (c) after elimination of Aliabad. 


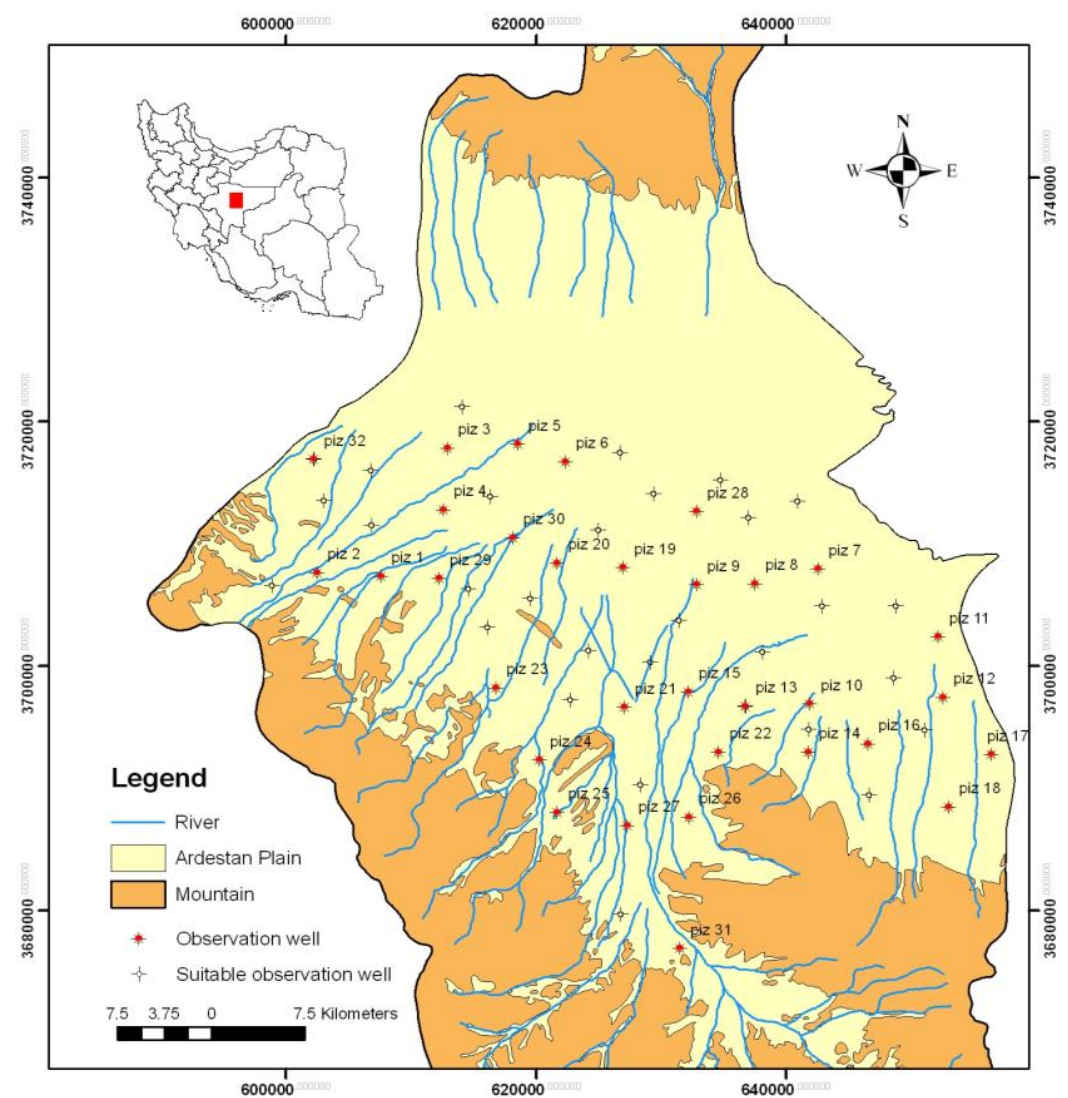

Figure 4. Location of the new boreholes.

eliminated from network.

After determining the points which must be eliminated from the network, new points which must be eliminated from the network, new points must be determined in order to reach to the optimum network. To determine such points, the following phases have been performed:

1. Determining limits and geometry of aquifer regarding hydrogeology and geophysics studies of Ardestan Plain, limits and geometry of aquifer have been completely determined.

2. Network working: network working has been done with acceptable compression $\left(5 \times 5 \mathrm{~km}^{2}\right)$.

3. Creating required layers: required layers such as route and adits, residental and agricultural rgions have been extracted from maps of the region with scale of 1:25000.

4. Considering limits of surface and ground water resources: considering limits of surface and ground water resources, especially existing wells, qanats and rivers in the region is so significant to supply this consideration, hydrogeology map of water resources has been used (these limits were determined by considering buffer in GIS) ESRI (2001).

5. Using results of geostatistical methods: regarding existing standard deviation map of the network, regions which have weak estimation can be determined, and borehole can be added in this reasons as far as possible. By considering above-mentioned matters in GIS, the best situation to be added to considered cell would be selected. In case that due to mentioned reasons no points can be added in any part of the cell, it would stay empty. After performing phases above in Ardestan Plain, thirty two points have been selected as proper points (Figure 4).

Now, by using geostatistical methods, the best combination and situation of points which create the least standard deviation in network can be determined.

\section{ADDING BOREHOLES WITH TRY AND ERROR}

Regarding 32 proper points, various combination of observation well location and their number can be considered to be added to the network. By using software $\mathrm{Gs}^{+}$, and adding various numbers and combinations of observation well, and with try and error method, the best measurement points to be added to network were determined.

Regarding estimation standard deviation map in network, various combinations of proper points can be tested in regions which show high standard deviation, and by adding points in which, estimation standard 


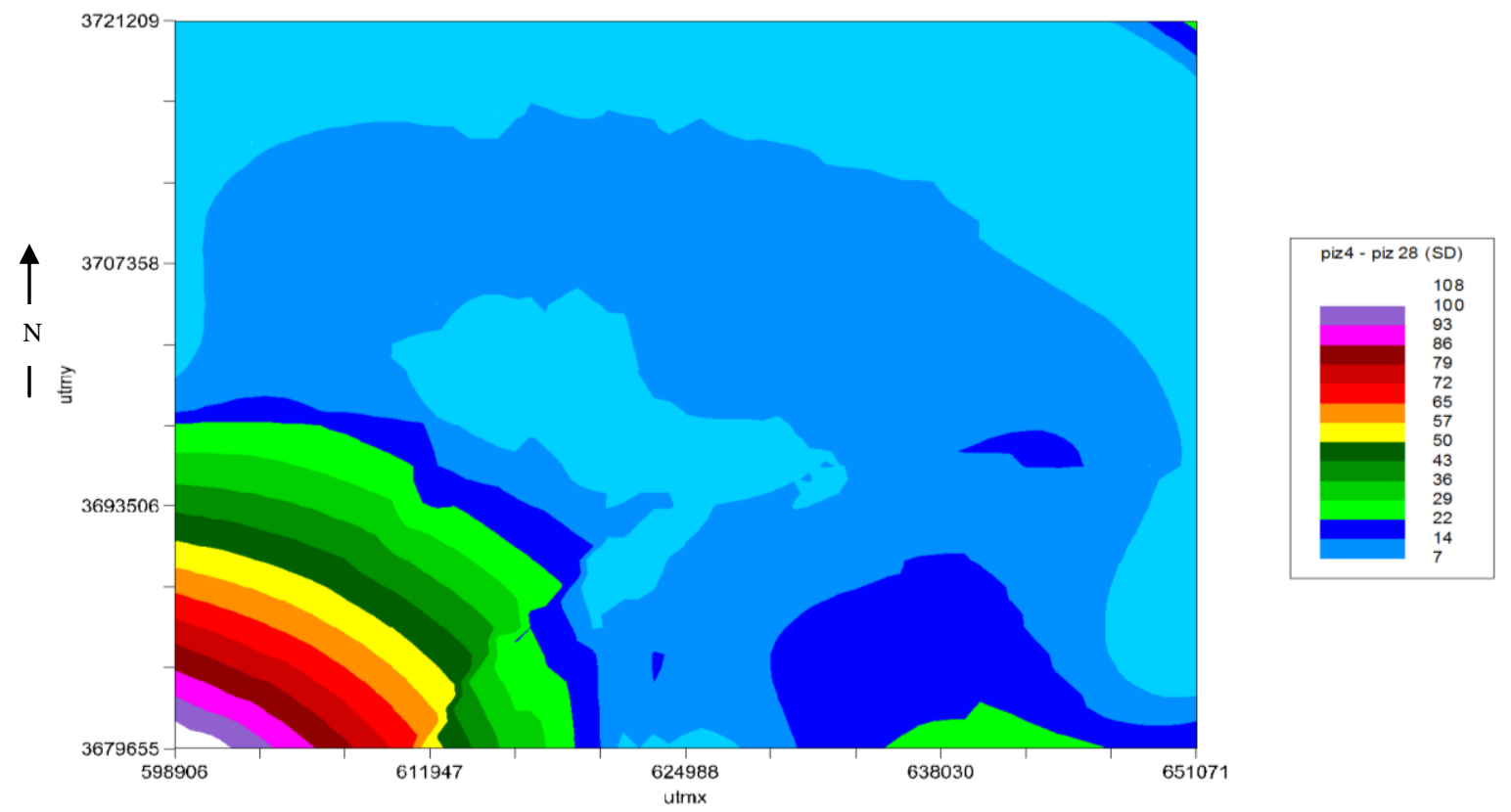

Figure 5. Iso standard deviation map after adding boreholes $P_{4}$ and $P_{28}$.

deviation would decrease.

By some steps of displacement of combination and suggested points, and also by accepting a determined standard deviation to estimate water table in those points, ultimately, the best combination of points to be added to network would be defined (Figure 5).

\section{ADDING BOREHOLE WITH COMPUTERIZED MODEL}

In order to add observation well in the plain, since combination and number of selected observation well are various, specially to add more combinations, and due to increase of probabilities, calculations with try and error method would be so difficult and time consuming. Accordingly, by benefiting from software Excel, a computer program has been prepared. This model has been prepared assuming that two observation wells would be added to network. Therefore, all probable states of adding observation well can be examined automatically in short time with maximum exactness.

In this method, by adding two observation wells $P_{15}$ and $P_{31}$, the least estimation variance was created in the network. Ultimately, by considering information of the new network in $\mathrm{Gs}^{+}$, the network has been analyzed (Figure 6) Flow chart of steps of prepared model is presented in Figure 7.

\section{WATER TABLE (BEFORE AND AFTER OPTIMIZATION)}

After elimination of unnecessary piezometers and adding piezometers as it was explained before, in last step, water tables can be compared before and after optimiziation. Figure $8 \mathrm{a}$ shows water table before optimization. According to iso-standard deviation map, in center of the plain and towards the corners has high standard deviation. After elimination of Kachoumesghal piezometer, standard deviation not only doesn't increase but also decreases and estimation of water table improves (Figure 3b). In step of adding two observation wells, this standard deviation in aquifer area decreases considerably and water table approaches to its ideal state (Figure 8c). It need to be mentioned that optimized water table modelizes direction of entered flow from south of Ardestan Plain and created gradian from Shour Dagh Sorkh aquifer in north.

\section{CONCLUSION}

In step of eliminating observation well by using evaluation technique in software $\mathrm{Gs}^{+}$, it turned out although network compression is less than acceptable limit, two observation wells have conditions of being eliminated from the network.

These two observation wells were eliminated from network separately, and analysis of network showed that elimination of Kachoumesghal caused estimation error to decrease, as well. In step of adding, both try and error and computerized model methods indicated decrease of estimation error in state of adding two observation wells. By adding these two observation wells in $1400 \mathrm{~km}^{2}$ area of the aquifer, network compression gets to 0.5 , This value has still so different from acceptable compression, while 


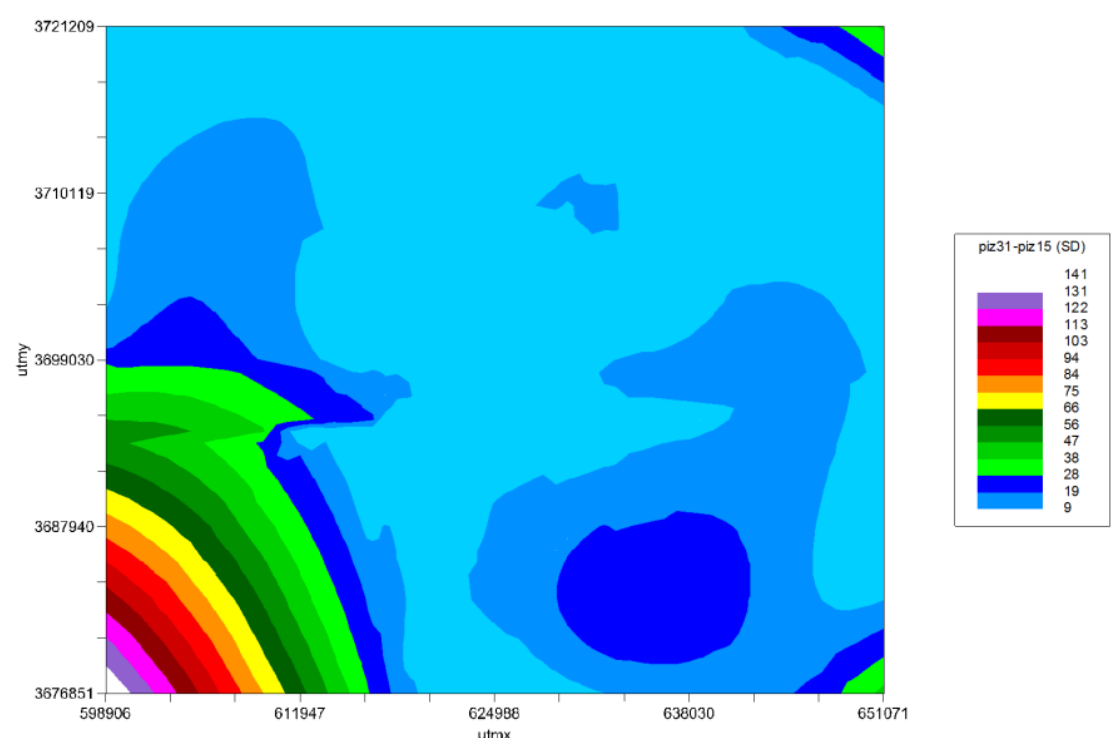

Figure 6. Iso standard deviation map after adding boreholes $P_{15}$ and $P_{31}$.

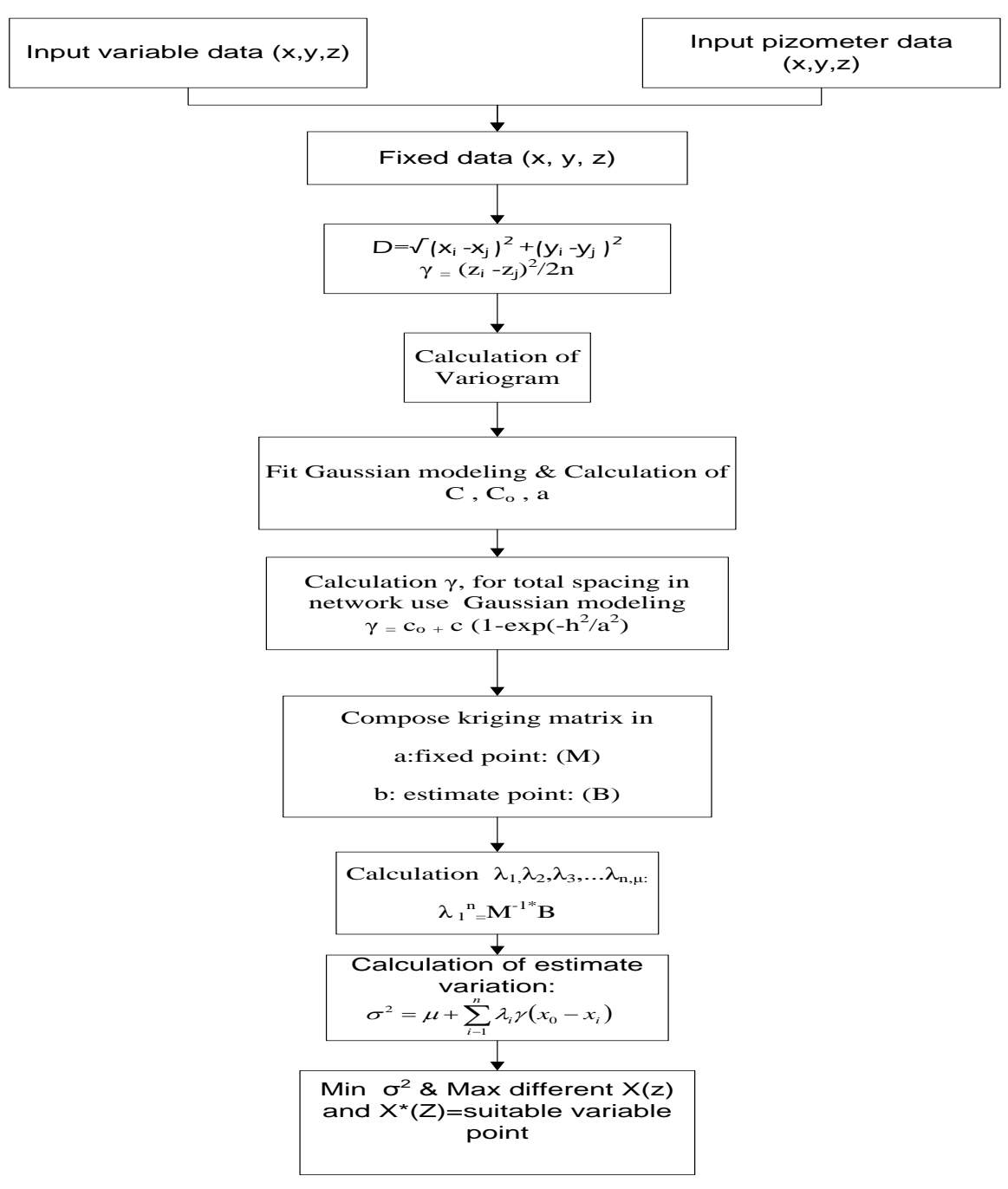

Figure 7. Flow chart of steps of prepared model. 


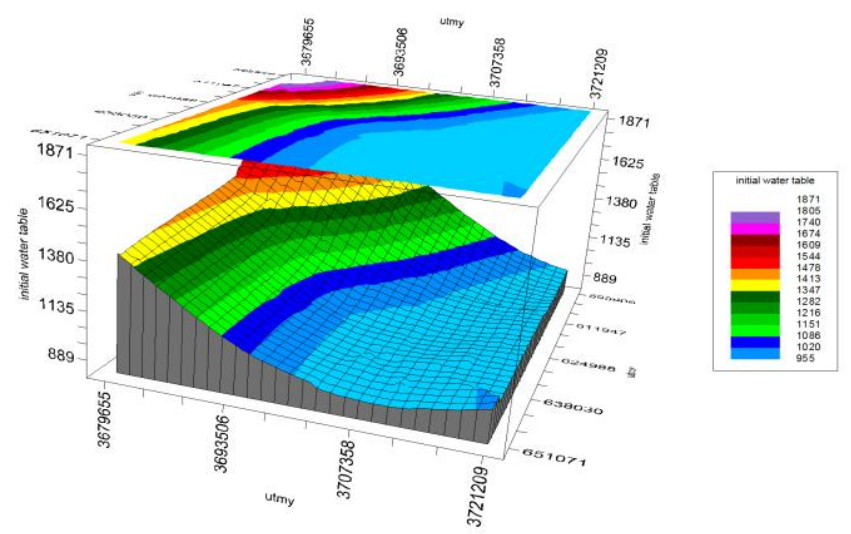

(a)

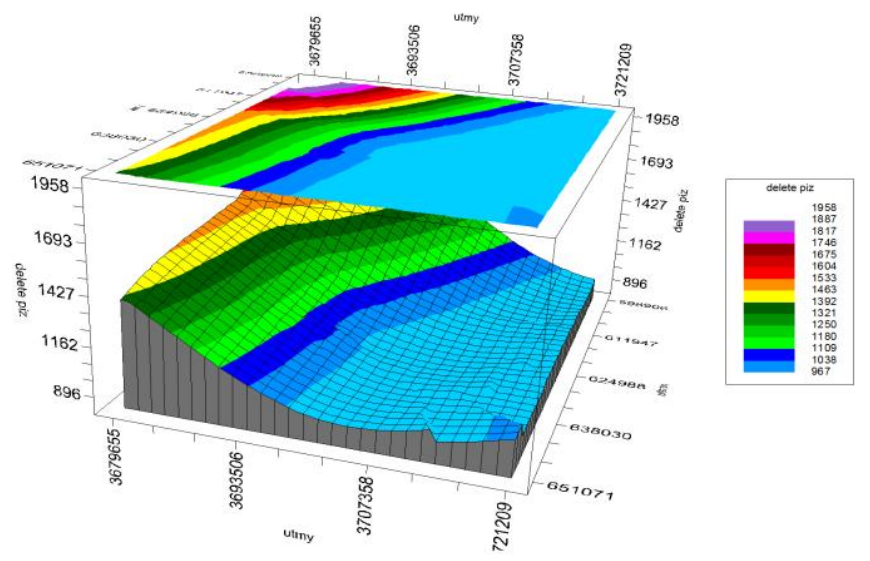

(b)

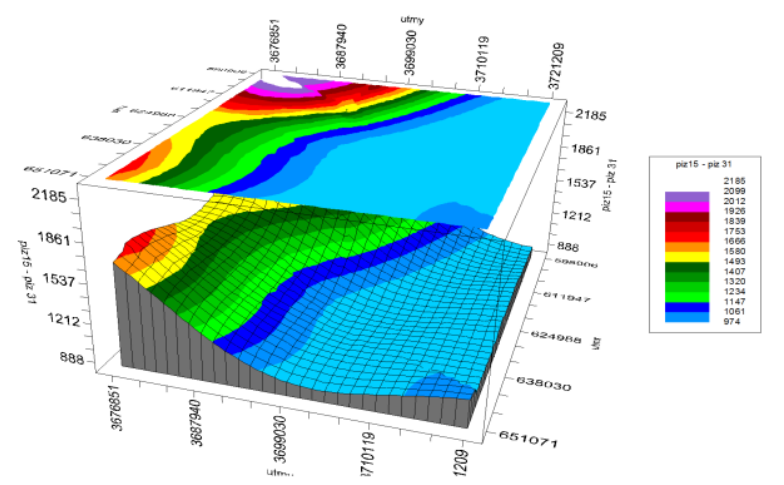

(c)

Figure 8. Iso water table map, (a) befor obtimization in Ardestal Plain, (b) after elimination Kachomesghal borehole (c) after obtimization.

estimation error in the plain is so decreased. Regarding results of optimizing quantitative network of Ardestan Plain, in normal conditions of the aquifer, by using geostatistical methods and hydrogeology studies, the network can be optimized such a way that low compressions have same and even better results in comparison with acceptable and high compressions. Accordingly all networks with high compression are not necessarily suitable and vice versa all networks with low compression are not necessarily unsuitable. As a result, 
in order to reach the representative network of aquifer, hydrogeology studies as well as geostatistics studies can be beneficial.

\section{REFERENCES}

Araghinejad S, Burn DH (2005). Probabilistic forecasting of hydrological events using geostatistical analysis. Hydrol. Sci. J. 50:837-856.

Bogardi I, Bardossy A, Duckstein L (1985). Multicriterion Network Design Using Geostatistics Water. Resour. Res. 21(2):199-208.

ESRI (2001). Using ArcGIS Geostatistical Analyst, ESRI, California.
Hughes JP, Lettenmaier P (1984). Data requirements for Kriging: Estimation and Network Design, Water. Resour. Res. 17(6):16411650.

Hudak PF, Loaiciga HA (1993). An optimization method for monitoring network design in multilayered Groundwater flow system. Water Resour. Res. 29(8):1835-1845.

Kumar VR (2006). Kriging of groundwater leval. J. Spatial hydrol. 6:8194.

Kitanidis PK (1995). Quasi-linear geostatical theory for inversing. Water Resour. Res. 31(10):1411-1419.

Sophocleous M, Paschetto E, Olea RA (1982). Groundwater Network design for Northwest Kansas, Using the Theory of Regionalized Variables. Groundwater 20(1):48-58. 